\title{
İlkokul Düzeyinde Yapılan Yaratıcı Drama Temelli Çalışmaların İncelenmesi
}

\author{
Tolga GÜRBÜZ \\ İstiklal İlkokulu, Kırıkkale \\ hocatolga92@gmail.com \\ ORCID ID: 0000-0003-3260-5007 \\ Veli TOPTAŞ \\ Kırıkkale Üniversitesi \\ vtoptas@gmail.com \\ ORCID ID: 0000-0001-8852-1852
}

\begin{tabular}{lrr} 
Araştırma Makalesi & DOI: $10.31592 /$ aeusbed.810709 \\
\hline Geliş Tarihi: 14.10 .2020 & Revize Tarihi: 06.11 .2020 & Kabul Tarihi: 13.11 .2020
\end{tabular}

\section{Atıf Bilgisi}

Gürbüz, T. ve Toptaş, V. (2020). İlkokul düzeyinde yapılan yaratıcı drama temelli çalışmaların incelenmesi. Ahi Evran Üniversitesi Sosyal Bilimler Enstitüsü Dergisi,6(3), 879-891.

\section{ÖZ}

Bu araştırma, Türkiye' de ilkokul matematik dersinde yaratıcı drama yönteminin kullanılmasına yönelik 2005-2020 yılları arasında yapılmış makale ve bilimsel toplantılarda sunulan bildiri çalışmalarını değerlendirmek ve bu çalışmaların genel durumunu belirlemek amacı ile yapılmıștır. Literatür taraması sonucu ilkokul matematik dersinde yaratıcı drama yönteminin kullanılmasına yönelik 2005-2020 yılları arasında yayınlanan makalelerin alan yazın araştırması sonucunda 6 çalışmaya ulaşılmıştır. Araştırmanın örnekleminde hakemli dergilerde yayınlanmış 5 makale ve 1 tanesi bilimsel toplantılarda sunulan bildiri olmak üzere 6 çalışma bulunmaktadır. İlkokulda yaratıcı drama yöntemiyle matematik öğretimi ile ilgi ulaşılan makale çalışmalarında en çok nitel araştırma yönteminin daha sonra ise nicel araştırma yönteminin kullanıldığ 1 tespit edilmiştir. Ayrıca çalışmalarda en çok durum çalışması deseni tercih edilmiştir. Çalışmalarda örneklem grubu olarak en fazla 4. sınıf öğrencileri yer almaktadır. Yaratıcı drama yöntemiyle yapılan ders planlarında en fazla sayılar ve işlemler öğrenme alanına yönelik kazanımlar yer almaktadır. Çalışmaların verileri çoğunlukla likert tipi ölçekle toplanmıştır. Çalışmaların hepsinde yaratıcı drama yöntemiyle yapılan ilkokul matematik derslerinin incelenen değişkenler üzerinde olumlu etkiler gösterdiği sonucuna ulaşılmıştır. Bu araştırmanın ilgili alanda yapılacak çalışmalara yardımcı olarak yön vereceği düşünülmektedir.

Anahtar Kelimeler: İlkokul, matematik, yaratıcı drama, literatür taraması.

\section{Review of Creative Drama Based Studies Conducted at Primary School Level}

\begin{abstract}
In this study, Turkey's elementary mathematics for the use of the method of creative drama classes conducted in the years 2005-2020 Report article and evaluate their work presented at scientific meetings and were made with the aim to determine the overall status of this work. As a result of the literature review, 6 studies were reached as a result of the literature research of the articles published between 2005 and 2020 on the use of creative drama method in primary school mathematics lesson. The sample of the study includes 5 articles published in peer-reviewed journals and 6 studies, one of which was presented at scientific meetings. It was determined that in the article studies, which were about teaching mathematics with creative drama method in primary school, qualitative research method was used the most, and then quantitative research method was used. In addition, the case study design was preferred mostly in the studies. The sample group included in the studies is mostly 4 th grade students. In the lesson plans prepared with the creative drama method, most numbers and operations are included in the learning area. In the studies, the data were collected mostly with Likert type scales. In all of the studies, it was concluded that primary school mathematics lessons conducted with the creative drama method had positive effects on the variables examined. It is thought that this research will guide the studies to be conducted in the related field.
\end{abstract}

Keywords: Primary school, mathematics, creative drama, literature review.

\section{Giriş}

Gelişen dünyada Fen, Teknoloji, Mühendislik ve Matematik gibi temel bilim dallarının önemi her geçen gün daha da artmaktadır. Temel bilim alanlarında matematiğe ihtiyaç duyulduğu gibi günde- 
lik hayatımızın en temel ihtiyaçlarının karşılanmasında matematik vazgeçilmezimiz olmuştur (Kilıçkaya ve Toptaş, 2017, s. 21). Matematik, aritmetik, cebir, geometri gibi sayı ve ölçü temeline dayanarak, niceliklerin özelliklerini inceleyen bilimlerin ortak adı, örüntü ve ilişkiler bilimidir (Olkun ve Toptaş, 2016, s. 184). Matematik, günlük hayattaki problemleri çözmede kullandığımız sayma, hesaplama, ölçme ve çizme işlemleri, kendine has bazı sembolleri olan bir dil, mantıksal düşünmeyi geliştiren mantıksal bir sistem, dünyanın anlamlandırılmasında ve yaşanan çevrenin geliştirilmesinde başvurulan bir yardımcıdır. Matematik yalnızca bunlardan birisi değil bunların tümüdür (Alakoç, 2003, s. 43).

Matematik denildiği zaman sayılar, şekiller, semboller ve bunların birleşmesinden meydana gelen kurallar akla gelmektedir. Aslında matematik sanıldığı kadar karmaşık bir yapıya sahip değildir. Bir dili öğrenmek için o dile ait temel gramer kuralları öğreniliyorsa matematikte bu şekilde öğrenilebilir (Kösece ve Taşkaya, 2015, s. 958). Günümüzde artan toplumsal ihtiyaçlar matematiği öğrenmeyi gerekli kılmaktadır. Matematiği öğrenmenin yollarından biri de iyi bir matematik eğitiminden geçmektedir.

Matematik eğitiminin en önemli amacı hayatta karşılaştığımız sorunları, problemleri çözüme kavuşturmaktır. Bir problemi anlayıp zihnimizde benzer problemlerle ilişkilendirip olası çözümler için yaklaşımları canlandırmak, problemi çözene kadar zihinsel aktiviteleri devem ettirmek gerekir. Bunlar1 yapabilmek için de yaratıcı olmak gerekmektedir. Amacı bireyi yaşama hazır hale getirmek olan eğitimin yeterli düzeyde olması gerekir. Eğitimin yeterli düzeyde olması için gereken konulardan birisi de eğitimde kullanılan yöntem ve tekniklerdir. Eğitim-öğretimde kullanılan yöntem ve teknikler amaca uygun olmalıdır. Bu amaçla birçok öğretim yöntem ve teknikleri geliştirilmektedir (Özsoy, 2003, s. 112).

Öğretmenlerin matematik öğretimindeki davranışları ve görüşleri üzerine birçok araştırma yapılmıştır. Bu araştırmaların sonuçlarına göre alanyazında geçen matematik öğretiminde kullanılan bazı yöntem ve teknikler şunlardır: Akıl yürütme, alıştırma yöntemi, analizle öğretim yöntemi, analoji, anlatım yöntemi, bilgisayar destekli öğretim, buzz yöntemi, deney, enneagram, etkinlik temelli, gösterip yaptırma yöntemi, hikâyelerle öğretim, iş başında öğretim yöntemi, kavram haritası, kurallarla öğretim, matematik tarihi, matematiksel modelleme, origami, oyunla öğretim, örnek olay yöntemi, problem çözme, proje yöntemi, senaryo ile öğretim, soru cevap yöntemi, şarkılarla öğretim, şifreleme, tahmin, tanımlar yardımıyla öğretim, tartışma yöntemi, yaratıcı drama (Kösece ve Taşkaya, 2015, s. 959). İlkokul matematik öğretiminde öğrencilerin derse aktif olarak katılımını sağlayacak, öğrenmelerini eğlenceli hale getirecek, özgüvenini yükseltecek, yaratıcılıklarını geliştirecek, matematiğe karşı olum tutum geliştirmelerine katkıda bulunacak yöntemlerden birisi de yaratıcı drama yöntemidir.

Yaratıcı drama, gözlem yapma, doğaçlama, rol oynama, dramatizasyon gibi tiyatro tekniklerinden yararlanılarak çeşitli yaşam durumlarını canlandırma, onları yeniden yaratıp irdeleyebilme, bu durumlardan bilgilenme ve öğrenmeye geçme çalışmalarıdır. Yaratıcı drama kullanılabilirliğini en çok eğitimde kanıtlamıştır (San, 1994, s. 69). Yaratıcı eğitim alanında hemen hemen her derste ve konuda yöntem olarak kullanılabilir.

Bir yöntem olarak drama, etkili öğrenmeye ortam sağlar. Drama ile öğrenci aktiftir, öğrendiği bilgiler ile yaşamındaki deneyimler arasında bağ kurar, grup çalışmasına katılıp motive olur. Kendi yaşamını işe koştuğu için kendini konunun bir parçası olarak görür ve böylece derse ilgisi artar. Herhangi bir derste drama yöntemi kullanılabilir. Çünkü dramanın temelinde yaratıcılık vardır. Drama öğretmen merkezli değil, öğrenci merkezli bir eğitim yöntemidir. Önemli olan, öğrencinin yaratıcılı̆̆ını harekete geçirmek, bilgiye ulaşmanın yollarının sunmaktır (Karadağ ve Çalışkan, 2006, s. 47). Bir yöntem olarak kullanılan yaratıcı drama derslerinin yapılandırılmasında belli aşamalar bulunmaktadır. Bu aşamalar:

1. Isınma-hazirlik,

2. Canlandırma, 


\section{Değerlendirme-Tartışma şeklindedir.}

Isınma-Hazırlık: Bir yaratıcı drama atölyesinde ilk olarak yer verilen çalışmalardır. Bu çalışmalarda grubu oluşturan bireylerin birbiriyle bütünleşmesine yönelik alıştırmalara yer verilir. Tanışma ile başlayan, güven kazanma, uyum sağlama, beş duyuyu kullanmayla devam eden ve gözlem yetisini geliştirmeyle, bedenini, beynini duyumsamayla sürdürülen çalışmalar bu aşamada yer alır (Üstündağ, 1998, s. 32)

Canlandırma: Bir konunun süreç içinde biçimlenip ortaya çıktığı, belirlendiği, biçimlendirildiği tüm oluşum çalışmalarının yapıldığı aşamadır. Canlandırılacak konu çerçevesinde bir başlangıç noktası olan, doğaçlama, rol oynama ve diğer tekniklerin kullanıldığı bir aşamadır. Yaratıcı drama çalışmalarındaki tüm yaşantılar, paylaşımlar, değerlendirmeler bu aşamada yapılan oluşum çalışmaları ile oluşan canlandırmalara, sonuçlarına ve bireyde bıraktığı izlere göre yapılır (Adıgüzel, 2006, s. 26).

Değerlendirme-Tartışma: Drama çalışmalarında elde edilen sonuçlar bu aşamada değerlendirilir. Başka bir deyişle, sürecin özü, önemi, niteliği ve niceliği bu aşamada saptanır. Duygular, düşüncelerin paylaşımı da bu aşamada alınır. Genel olarak eğitsel kazanımlar üzerine ya da ortaya çıkan oluşumlar üzerine tartışmalar bu aşamada yapılır. Öğrenilenlerin kazanıma dönüşüp dönüşmediği ve bu durumun gelecek yaşantılara etkisinin olup olmayacağı, tüm drama yaşantı ve süreçlerinin nasıl algılandığı, anlaşıldığına yönelik duygu ve düşüncelerin paylaşılması bu aşamada söz konusudur (Adigüzel, 2006, s. 26)

İlgili alan yazın incelendiğinde yaratıcı drama ile ilgili birçok çalışma yapıldığı görülmektedir. İlkokul matematik dersinde yaratıcı drama yönteminin kullanılmasına ilişkin çalışmaların azda olsa görüldüğü halde bu alanda yapılan araştırmaların değerlendirilmesini yapan alanyazın çalışmasına rastlanılmamıştır. Alanyazın incelemesinin konu ile ilgili yapılmış çalışmaları derleyip yapılacak olan yeni çalışmalara ışı tutması bakımından faydalı olacağı söylenebilir. Ayrıca araştırmanın bu alanda yapılacak çalışmalara yön vereceği düşünülmektedir. Bu noktadan hareketle araştırmada, Türkiye' de ilkokul matematik dersinde yaratıcı drama yönteminin kullanılmasına yönelik 2005-2020 yılları arasında yapılmış çalışmaları değerlendirmek ve bu çalışmaların genel durumunu belirlemek amaçlanmıştir.

Bu araştırma, Türkiye'de ilkokul matematik dersinde yaratıcı drama yönteminin kullanılmasına yönelik 2005-2020 yılları arasında yapılmış makale çalışmalarını değerlendirmek ve bu çalışmaların genel durumunu belirlemek amacı ile yapılmıştır. Bu amaçla aşağıdaki araştırma sorularına cevap aranmıştır:

1. İncelenen çalışmaların yıllarına ve türlerine göre dağılımı nasıldır?

2. İncelenen çalışmalarda kullanılan yöntem ve teknikler nelerdir?

3. İncelenen çalışmalardaki örneklem kimlerden oluşmaktadır?

4. İncelenen çalışmalar matematik dersi öğrenme alanlarına göre nasıl bir dağılım göstermektedir?

5. İncelenen çalışmalarda kullanılan veri toplama araçları nelerdir?

6. İncelenen çalışmaların ilişkilendirildiği değişkenler nelerdir?

7. İncelenen çalışmalar sonuçlarına göre nasıl bir dağılım göstermektedir?

\section{Yöntem}

Bu bölümde sırasıyla araştırma modeli/deseni, evren ve örneklem, veri toplama araçları, verilerin toplanması ve analizine yer verilmiştir. 


\section{Araștırma Modeli/Deseni}

Bu araştırmada, Türkiye'de ilkokul düzeyinde yapılan yaratıcı drama temelli matematik öğretimi makale ve bilimsel toplantılarda sunulan bildiri çalışmalarını derlemek amacıyla nitel araştırma yöntemi ve literatür tarama deseni tercih edilmiştir. Nitel araştırma, gözlem, görüşme ve doküman analizi kullanılarak algıların ve olayların doğal ortamda gerçekçi bir şekilde ortaya konmasıdır (Yıldırım ve Şimşek, 2008, s. 39). Literatür taraması, sizin ilgilendiğiniz konuya ilişkin bilgileri bulmanızı, araştırmanıza kuramsal bir temel kazandırmanızı ve sizinkine benzer çalışmaların sonuçlarını görmenizi sağlar. Araştırmanız sonucunda elde ettiğiniz sonuçları, diğer araştırma sonuçları ile karşılaştırarak farklılık ve benzerliklerin nedenleri hakkında fikir yürütmenize de yardımcı olur (Büyüköztürk ve arkadaşları, 2018, s. 47).

\section{Evren ve Örneklem}

$\mathrm{Bu}$ araştırmanın evrenini Türkiye'de matematik dersinde yaratıcı drama yönteminin kullanılmasına yönelik 2005-2020 yılları arasında hakemli dergilerde yayınlanmış makaleler ve bilimsel toplantılarda (sempozyum-kongre-konferans-çalıştay) sunulan bildiriler oluşturmaktadır. Araştırmanın örneklemi ise Türkiye'de ilkokul matematik dersinde yaratıcı drama yönteminin kullanılmasına yönelik 2005-2020 yılları arasında hakemli dergilerde yayınlanmış makaleler ve bilimsel toplantılarda (sempozyum-kongre-konferans-çalıştay) sunulan bildirilerden oluşmaktadır.

\section{Veri Toplama Aracı}

Bu araştırmada, Türkiye'de ilkokul matematik dersinde yaratıcı drama yönteminin kullanılmasına yönelik 2005-2020 yılları arasında yapılmış makale çalışmalara alanyazın taraması yapılarak ulaşılmıştır. Google Akademik (scholar.google.com, 2020) arama motorundan 2005-2020 y1lları arasında yayınlanan çalışmalar taranmıştır. Alanyazın taraması yapılırken ilkokul, matematik ve yaratıcı drama kodları kullanılmıştır. Alanyazın taraması sonucunda 6 adet çalışmaya ulaşılmıştır. Ulaşılan bu çalışmalar hakemli dergilerde yayınlanan makaleler ve bilimsel toplantılarda sunulan bildiriler adı altında incelenmiştir.

\section{Verilerin Toplanması ve Analizi}

$\mathrm{Bu}$ araştırmada amaca uygun olan çalışmalar anahtar kelimeler kullanılarak ve tek tek analiz edilerek Google Akademik (scholar.google.com, 2020) arama motorundan toplanmıştır. Ayrıca ulaşılan çalışmaların türlerine ve yıllarına göre dağılımı, çalışmalarda kullanılan yöntem ve teknikler, örneklem grupları, çalışmalarda kullanılan matematik dersi öğrenme alanları, veri toplama araçları, çaış̧maların ilişkilendirildiği değişkenler, sonuçlara göre dağılımları şeklinde yedi başlık altında analiz edilmiştir.

\section{Bulgular}

Bu bölümde, alan yazın taraması sonucunda elde edilen verilerin analizine yönelik bulgulara yer verilmiştir. Bulgular sunulurken alt problemlere göre düzenlenmiştir. 2005-2020 yılları arasında yayınlanan makalelerin yıllarına ve türlerine göre dağılımı Tablo 1'de sunulmuştur.

Tablo 1

İncelenen Çalışmaların Yıllara ve Türlere Göre Dağılımı

\begin{tabular}{lccc}
\hline Yll & Makale & Bilimsel Toplantilar & Toplam \\
\hline 2007 & 1 & 1 \\
2014 & 2 & 2 \\
\hline
\end{tabular}




\begin{tabular}{llll}
\hline 2015 & 1 & & 1 \\
2016 & 1 & 1 & 1 \\
2018 & & 1 & 1 \\
Toplam & 5 & 1 & 6 \\
\hline
\end{tabular}

Tablo 1'de yer alan sonuçlara göre, ilkokul matematik dersinde yaratıcı drama yönteminin kullanılmasına yönelik 2005-2020 yılları arasında yayınlanan makalelerin alan yazın araştırması sonucunda 6 çalışmaya ulaşılmıştır. Araştırma sonuçlarına göre, 2007, 2015, 2016 yıllarında birer tane ve 2014 yılında 2 tane olmak üzere toplam 5 tane hakemli dergide yayınlanan makaleye; 2018 yılında bir tane bilimsel toplantılarda sunulan bildiriye ulaşılmıştır. Bilimsel toplantılarda sunulan bildiri 2018 yılında yayınlanan tezden üretilmiştir. İncelenen çalışmalarda kullanılan yöntem ve desenlere ilişkin bilgiler Şekil 1'de verilmiştir.

\begin{tabular}{|l|l|}
\hline \multicolumn{1}{|c|}{ Araştıma Yöntemi } & Sayıs1 (f) \\
\hline Nicel & 2 \\
\hline Nitel & 3 \\
\hline Bilgilendirici Makale & 1 \\
\hline
\end{tabular}

\begin{tabular}{|l|l|}
\hline \multicolumn{1}{|c|}{ Araştıma Deseni } & Say1sı (f) \\
\hline Deneysel & 2 \\
\hline Durum Çalı̧̧ması & 3 \\
\hline $\begin{array}{l}\text { Bilgilendirici Makale } \\
\text { Etkinlik Ömekleri }\end{array}$ & 1 \\
\hline
\end{tabular}

Şekil 1. İncelenen Çalışmalarda Kullanılan Yöntem ve Desenler

Şekil 1'e göre ilkokulda yaratıcı drama yöntemiyle matematik öğretimi ile ilgi ulaşılan makale çalışmalarında en çok nitel araştırma yönteminin (f:3) daha sonra ise nicel araştırma yönteminin (f: 2) kullanıldığ 1 tespit edilmiştir. Ayrıca ulaşılan makalelerin bir tanesi yaratıcı drama yöntemiyle ilgili örnek ders planı örnekleri sunan bilgilendirici makaledir. Çalışmalarda en çok durum çalışması (f: 3 ) kullanılmıştır. Ayrıca çalışmalarda deneysel desenin (f: 2) kullanıldığı görülmektedir. Ulaşılan bilgilendirici makalede ise yaratıcı drama ile matematik öğretimine yönelik etkinlik örneklerine yer verilmiştir. Grafik 1'de incelenen çalışmalardaki örneklem grupları ile ilgili bilgiler yer almaktadır.

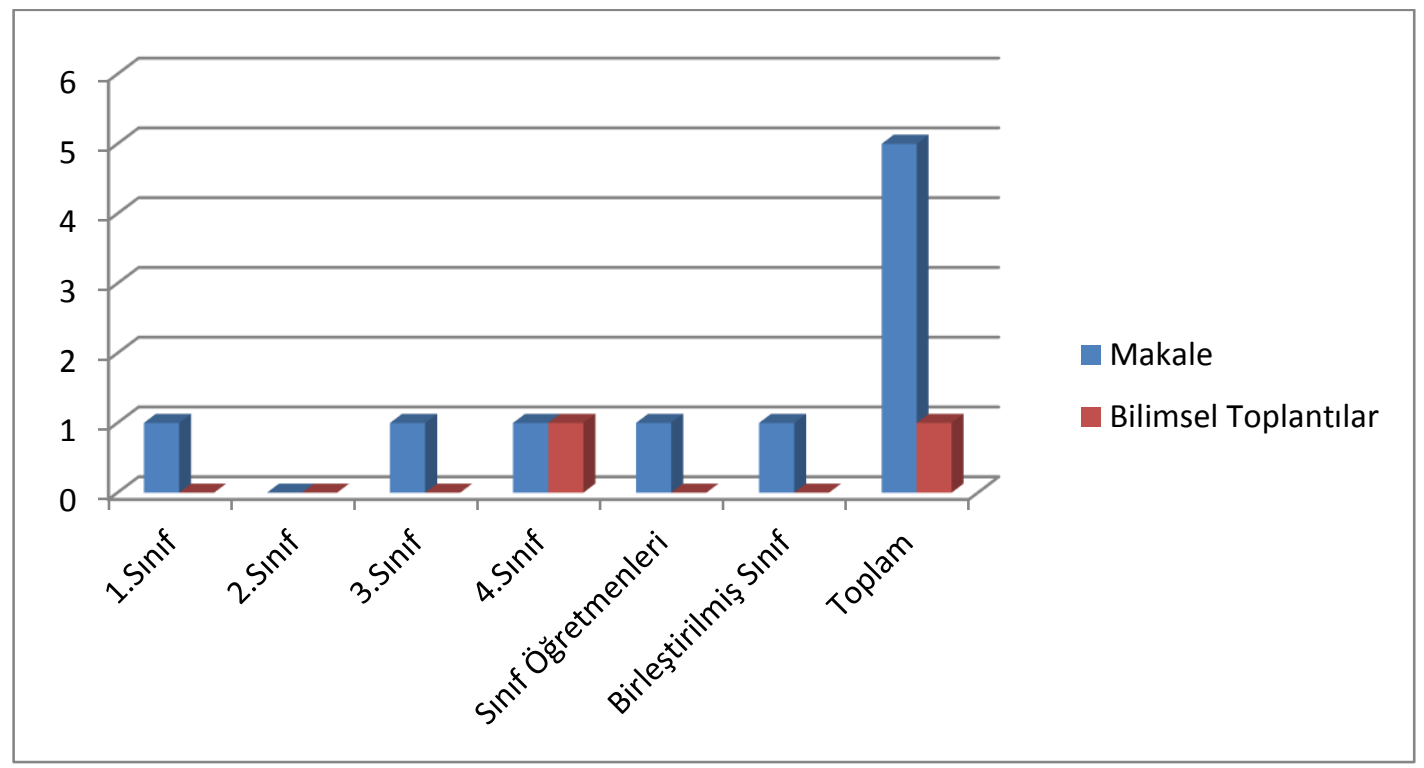

Grafik 1. İncelenen Çalışmalardaki Örneklemler Grupları

Grafik 1 incelendiğinde, 4 .sınıflarda 1 makale ve 1 bilimsel toplantı çalışmasına; 3.sınıflarda 1 makale çalışmasına; 1.snıflarda 1 makale çalışmasına; birleştirilmiş sınıflarda 1 makale çalışmasına; sınıf öğretmenlerinin görüşlerinin alındığ 1 makale çalışmasına rastlanmıştır. 4.sınıflarda yapılan 
çalışmaların diğer sınıflardan daha fazla olduğu görülmektedir. Ayrıca 2. sınıflarda yapılmış makale çalışmasına ulaşılmamıştır. Tablo 2'de incelenen çalışmalarda kullanılan matematik dersi öğrenme alanlarına ait bilgiler sunulmuştur.

Tablo 2. Incelenen Çalışmalarda Kullanılan Matematik Dersi Öğrenme Alanları

\begin{tabular}{lll}
\hline Sınıf Seviyesi & Öğrenme Alanı & Alt Öğrenme Alanı \\
\hline 1. Sınıf & Sayılar ve İşlemler & Doğal Sayılarla Toplama İşlemi \\
\hline 2.Sınıf & - & - \\
\hline 3.Sınıf & Ölçme & Uzunluk Ölçme \\
\hline \multirow{2}{*}{ 4. Sınıf } & Sayılar ve İşlemler & Kesirler \\
& Ölçme & Simetri \\
\cline { 2 - 3 } & & Kesirler \\
\hline Birleştirilmiş Sınıf & Sayılar ve İşlemler & \\
\hline
\end{tabular}

Tablo 2'de yer alan verilere göre, ilkokul matematik dersinde yaratıcı drama yönteminin kullanımına ilişkin yapılan çalışmaların sayılar ve işlemler öğrenme alanında yoğunlaştığı görülmektedir. Tablo 3'de incelenen çalışmalar da kullanılan veri toplama araçlarının bilgilerine yer verilmiştir.

Tablo 3. Incelenen Çalışmalarda Kullanılan Veri Toplama Araçları

\begin{tabular}{lccc}
\hline Veri Toplama Araçları & Makale & Bilimsel Toplantılar & Toplam \\
\hline Başarı Testi & 1 & 0 & 1 \\
Ölçek & 0 & 2 & 2 \\
Görüşme Formu & 0 & 1 & 1 \\
Gözlem Notları & 2 & 0 & 2 \\
Yarı Yapıllandırılmış Mülakat & 1 & 0 & 1 \\
Etkinlik Örnekleri & 1 & 0 & 1 \\
\hline
\end{tabular}

Tablo 3'e göre, incelenen çalışmalarda sırasıyla ölçek (f: 2) ve gözlem notları (f: 2), başarı testi (f: 1), görüşme formu (f: 1) ve yarı yapılandırılmış mülakatlar (f: 1) veri toplama aracı olarak kullanılmıştır. Bir makalede ise etkinlik örnekleri yer almaktadır. Ayrıca kullanılan ölçeklerin matematik kaygı ve motivasyon ölçekleri olduğu sonucuna ulaşılmıştır. Tablo 4'de incelenen çalışmaların ilişkilendirildiği değişkenlere ait bilgilere yer verilmiştir.

Tablo 4. İncelenen Çalışmaların İlişkilendirildiği Değişkenler

\begin{tabular}{lll}
\hline Araştırma Türü & Değişken & F \\
\hline Makale & Akademik Başarı & 1 \\
& Öğrenmelerin Kalıcılığı & 1 \\
& Öğrenci Görüşleri & 1 \\
& Yaratıcı drama yöntemi etkinlik örneği & 1 \\
& Betimleme & 1 \\
\hline Bilimsel Toplantılar & Matematik Kaygısı & 1 \\
& Matematik Motivasyonu & 1 \\
\hline
\end{tabular}

Tablo 4 incelendiğinde yaratıcı drama yöntemi kullanılarak yapılan makalelerde, başarı (f: 1), öğrenmelerin kalıcılığı (f: 1), öğrenci görüşleri (f: 1), yaratıcı drama yöntemi etkinlik örneği (f: 1), betimleme (f: 1) değişkenleri; bilimsel toplantılarda ise matematik kaygısı (f: 1), matematik motivasyonu (f: 1) değişkenleri incelenmiş. İncelenen çalışmaların hepsinde farklı değişkenler incelendiği görülmektedir. Grafik 2'de incelenen çalışmaların sonuçlarına göre dağılımları yer almaktadır. 


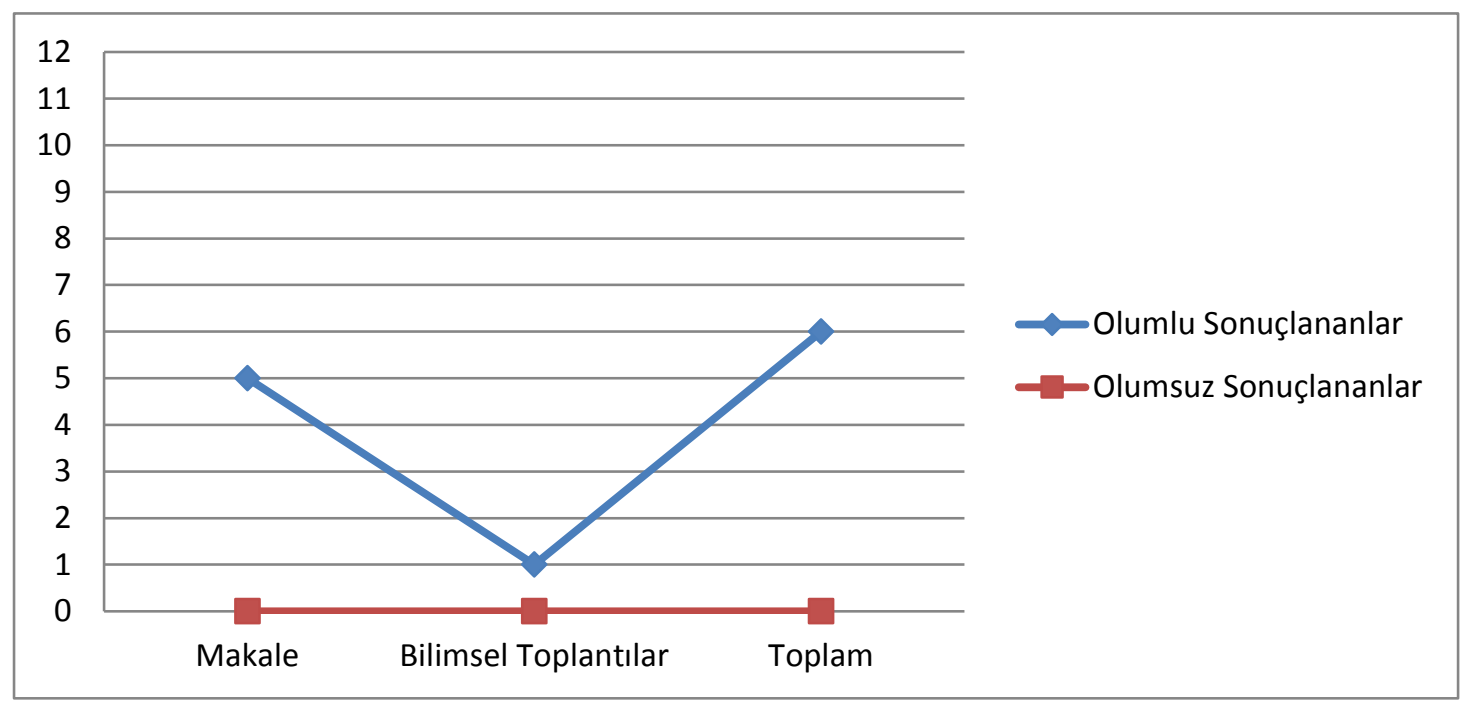

Grafik 2. İncelenen Çalışmaların Sonuçlarına Göre Dağılımları

Grafik 2’ye göre incelenen çalışmaların hepsinde olumlu sonuçlar elde edildiği görülmektedir.

\section{Sonuç, Tartışma ve Öneriler}

Bu araştırmada, Türkiye'de ilkokul matematik dersinde yaratıcı drama yönteminin kullanılmasına yönelik 2005-2020 yılları arasında yapılmış makale çalışmalarını ve bilimsel toplantılarda sunulan bildirileri değerlendirmek ve bu çalışmaların genel durumunu belirlemek amaçlanmıştır. Literatür incelemesi sonucu ulaşılan 6 kaynak, araştırmalarda kullanılan yöntem ve desen, örneklem grubu, matematik dersi öğrenme alanları, veri toplama araçları, ilişkilendirilen değişkenler, çalışmaların sonuçları göz önünde bulundurularak hakemli dergilerde yayınlanmış makaleler ve bilimsel toplantılar (sempozyum-kongre-konferans-çalıştay) sunulan bildiriler olmak üzere 2 farklı kategoride değerlendirilmiştir.

Ulaşılan 6 çalışmanın 5 tanesi hakemli dergilerde yayınlanmış makale ve 1 tanesi bilimsel toplantılarda sunulan bildiriden oluşmaktadır. Bilimsel toplantılarda sunulan bildiri daha önce yazılmış yüksek lisans tezinden üretilmiştir. Çalışmaların son yıllarda sayısının arttığı görülmektedir. Bu durum ilkokul matematik öğretiminde yaratıcı drama yönteminin kullanılmasına ilişkin ilginin arttığını göstermektedir. Her ne kadar sayısal olarak artış görünse de ilkokul matematik dersinde yaratıcı drama yönteminin kullanılmasına ilişkin yeterli sayıda araştırma bulunmamaktadır.

Yaratıcı drama sürecinin ilkokulda bir yöntem olarak kullanılmasının, ögrenciler açısından eğlenceli, etkili öğrenmeyi sağlayan ve öğrencilerin ders esnasında kendini rahat ifade edebileceği yönünde olumlu katkılar sunacağı söylenebilir (Aktepe ve Bulut, 2014, s. 1088). İlkokul matematik dersinde öğrencilerin eğlenerek öğreneceği, süreçte aktif olacağı ve yaratıcılıklarının gelişimine katkı sağlayacă̆ 1 bir ders için yaratıcı drama yöntemine daha fazla önem verilmesi ve yapılacak çalışmalarda yaratıcı drama yönteminin araştırmacılar tarafından değerlendirilmesi gerektiği söylenebilir.

Araştırmalarda en fazla nitel araştırma yönteminin kullanıldığı görülmektedir. Ulaşılan bir makale ise yaratıcı drama ile ilgili ders örneğinin olduğu bilgilendirici makaledir. Araştırmalarda kullanılan desenlere bakıldığında ise en fazla durum çalışmasının kullanıldığı tespit edilmiştir. Kayhan'ın (2012) yaptığı alanyazın çalışmasında ulaşılan araştırmaların büyük çoğunluğunun deneysel araştırmalar olduğu ve Calp ve Seçgin'in (2019) yapmış olduğu alanyazın araştırmasında ulaştığ 1 çalışmalarda en fazla nicel çalışmalara ulaştığı görülmektedir. Ulaşılan çalışmaların deneysel çalışmalarda geleneksel öğretim yöntemi ile yaratıcı drama yönteminin karşılaştırıldığı görülmektedir. İlkokul matematik 
öğretiminde kullanılabilecek alternatif yöntem ve tekniklerle yaratıcı drama yöntemi karşılaştırılarak hangi konunun hangi yöntemle daha etkili sonuçlar verdiği görülebilir.

İncelenen çalışmaların örneklemlerine bakıldığında 4. sınıflar iki, 3. sınıflarda bir, 1. sınıflarda bir, birleştirilmiş sınıflarda bir ve bir çalışmada da sınıf öğretmenlerinin görüşleri alınmıştır. Örneklemlerinin büyük çoğunluğunu 4. sınıflar oluştururken 2. sınıflarda hiç makale çalışmasına rastlanmamıştır. Büyük sınıf seviyelerinde daha fazla uygulama yapılmasının sebepleri arasında uygulama kolaylığının olduğu söylenebilir.

Çolak (2019) "1. Sınıf Öğrencilerine Çıkarma İşleminin Öğretiminde Drama Yönteminin Kullanımından Yansımalar" isimli tez çalışmasında nitel yöntem kullanarak 1. sınıf öğrencilerinin matematik dersi hakkındaki görüşlerini ve matematik dersinin sınıf içindeki yansımalarını incelemiştir. Araştırmanın sonucunda yaratıcı drama yönteminin matematik dersi için uygun bir yöntem olduğu sonucuna varılmıştır. Öztürk ve arkadaşları (2016) 1. sınıfta drama yöntemiyle toplama işleminin öğrencilere yansımalarını nitel araştırma yöntemiyle incelemiş ve öğrencilerin derse daha istekli katıldıklarını ve kendilerini daha rahat ifade ettiklerini görmüş. Sınıf seviyesi düştükçe uygulama zorluğu görülse de bu zorluklar uygun araştırma yöntem ve desenleriyle aşılabilir.

Ulaşılan çalışmalarda kullanılan konuların ilkokul matematik dersi "sayılar ve işlemler" öğrenme alanında yoğunlaştığı görülmektedir. Bu durum, yaratıcı drama yöntemiyle sadece "sayılar ve işlemler" öğrenme alanında dersler yapılabilir kanısı uyandırabilir. Hâlbuki yaratıcı drama birçok ders ve konu için etkili bir alternatif öğretim yöntemidir.

Araştırmalarda veri toplama aracı olarak en fazla likert tipi ölçeklerin kullanıldığı sonucuna ulaşılmıştır. Ayrıca ölçeklerde ise matematik kaygısı, motivasyonu ve tutum ölçeklerinin kullanımında yoğunluk görülmektedir.

Ulaşılan çalışmalarda ilkokul matematik dersinde yaratıcı drama yönteminin kullanılmasının öğrencilerin akademik başarılarına, tutumlarına, öğrenmelerinin kalıcılıklarına etkisinin incelendiği tespit edilmiştir. Ayrıca hemen hemen tüm çalışmalardaki değişkenlerin birbirini tekrar ettiği görülmektedir.

Araştırmalardan elde dilen verilere göre ulaşılan 6 çalışmanın da olumlu sonuçlar verdiği görülmüştür. Bu bilgilere bakılarak yaratıcı drama yöntemiyle işlenen derslerde öğrencilerin başarılarının, tutumlarının, matematik motivasyonlarının, matematik kaygılarının ve problem çözme becerilerinin yükseldiği, öğrenmelerin kalıcılığının arttığı, matematik dersi hakkındaki öğrenci görüşleri ve öğrenme ortamlarının olumlu hale geldiği söylenebilir. İlkokul matematik dersinde 2005-2020 yılları arasında yapılan makale çalışmalarının kapsamlı analizinin yapıldığ 1 bu çalışmanın, bu alanda yapılacak olan yeni çalışmalar için aydınlatıcı bir rehber olacağı ve alandaki eksiklikleri görmek ve çözüm önerileri geliştirmek için faydalı olacă̆ düşünülmektedir.

Tüm bu değerlendirmelerden yola çıkarak yaratıcı dramanın ilkokul matematik dersinde öğretim yöntemi olarak kullanılmasına yönelik şu önerilerde bulunulabilir:

1. Çalışmalarda kullanılan örneklem gruplarının daha çok 4.sınıflardan oluştuğu görülmektedir. Yaratıcı drama yönteminin uygun araştırma teknikleriyle daha düşük seviyedeki örneklem gruplarına uygulaması yapılabilir.

2. Çalışmalarda yaratıcı drama ile geleneksel öğretimin karşılaştırıldığı deneysel çalışmalara ulaşılmıştır. Yapılacak olan yeni araştırmalarda yapılandırmacı yaklaşıma uygun matematik öğretiminde kullanılacak alternatif teknikler ile yaratıcı drama yöntemi karşılaştırılabilir.

3. Bulgular sonucunda, yapılan çalışmaların sayılar ve işlemler öğrenme alanında yoğunlaşma olduğu görülmektedir. Yaratıcı drama yöntemi ile ilkokul matematik dersine ait diğer öğrenme alanlarında çalışmalar yapılabilir. 
4. Yaratıcı drama yönteminin ilkokul matematik dersinde kullanılmasına dair daha geniş örneklem grubu ele alınarak literatür çalışması yapılabilir.

\section{Kaynaklar}

Adıgüzel, Ö. (2006).Yaratıcı drama kavramı,bileşenleri ve aşamaları. Yaratıcı Drama Dergisi, 17-29.

Aktepe, V. ve Bulut, A. (2014). yaratıcı drama destekli matematik öğretimin öğrencilerin akademik başarısına etkisi. Kastamonu Ĕ̌itim Dergisi, 1081-1090.

Alakoç, Z. (2003). Matematik öğretiminde teknolojik modern öğretim yaklaşımları. The Turkish Online Journal of Educational Technology, 43-49.

Altındal, G. (2019). Illkokul 3. sınıf matematik dersinde yaratıcı drama yönteminin öğrencilerin başarılarına, tutumlarına ve bilgilerinin kalıcllı̆ğna etkisi Yüksel Lisans Tezi, Aksaray Üniversitesi Sosyal Bilimler Enstitüsü, Aksaray

Bakkaloğlu, N. (2012). Drama yönteminin ilköğretim 4.sınıf matematik dersinde öğrenmenin kalıcılığına etkisi, https://scholar.google.com/ adresinden Erişim 18 Nisan 2020 tarihinde erişilmiştir.

Borlat, G. (2018). Yaratıcı drama yönteminin matematik kaygısı ve motivasyonuna etkisi, Yüksek Lisans Tezi, Çanakkale On Sekiz Mart Üniversitesi Eğitim Bilimleri Enstitüsü, Çanakkale

Borlat, G. (2018, Ekim 5-7). Yaratıcı drama yönteminin matematik kaygısı ve matematik motivasyonuna etkisi, I. Uluslararası Sosyal Bilimlerde Kritik Tartışmalar Kongresi

Büyüköztürk, Ş., K1lıç Çakmak, E., Akgün, Ö., Karadeniz, Ş., ve Demirel, F. (2018). Bilimsel araştırma yöntemleri. Ankara: Pegem Akademi.

Calp, Ş. ve Seçgin, M.G. (2019). Türkiye'de yaratıcı drama alanında yapılmış tezlere yönelik betimsel bir analiz. Türkiye Sosyal Araştırmalar Dergisi, 365-388

Çolak, G. (2019). 1.sınıf öğrencilerine çıkarma işleminin öğretiminde drama yönteminin kullanımından yansımalar, Yüksek Lisan Tezi, Trabzon Üniversitesi Lisansüstü Eğitim Enstitüsü, Trabzon

Karadağ, E. ve Çalışkan, N. (2006). İlköğretim birinci kademesi öğrencilerinin drama yöntemine karş1 tutumlarının değerlendirilmesi.Pamukkale Üniversitesi Ĕgitim Fakültesi Dergisi , 45-57.

Kayhan, H.C., (2012). Türkiye'deki drama ağırlıklı matematik öğretimi çalışmaları üzerine bir değerlendirme. Mustafa Kemal Üniversitesi Sosyal Bilimler Enstitüsü Dergisi, 97-120

K1lıçkaya, M. ve Toptaş, V. (2017). Problem çözme: literatür incelemesi. Ijetsar (International Journal Of Education Technology and Scientific Researches), 20-31.

Kösece , P. ve Taşkaya, S. (2015). Sınıf öğretmenlerinin matematik dersi öğretim yöntemlerine ilişkin görüşlerinin incelenmesi.International Periodical For The Languages, Literature and History of Turkish or Turkic , 955-970.

Mutlu Aydın, S. (2013). Türkiye'de ilkokul dördüncü sınıfta yapılan yaratıcı drama etkinliklerinin ögrencilerin problem çözme becerisine etkisi, Yüksek Lisan Tezi, Atatürk Üniversitesi Eğitim Bilimleri Enstitüsü, Erzurum

Olkun, S. ve Toptaş, V. (2016). Resimli matematik terimleri sözlü̆̆̈̈. Ankara: Son Çağ. 
Özsoy, N. (2003).ílköğretim matematik derslerinde yaratıcı drama yönteminin kullanılması BAÜ Fen Bil. Enst. Dergisi, 112-119.

Özsoy, N., Yüksel, S. (2007). Matematik öğretiminde drama, Dokuz Eylül Üniversitesi Buca Eğitim Fakültesi Dergisi, 21: 32-36

Öztürk, M., Akkan, Y., Kaplan, A., Oktay, E. (2016). Drama yöntemiyle toplama işlemi: ilkokul birinci sınıf öğrencilerinden yansımalar, Kastamonu Eğitim Dergisi, Cilt:24 No:1, 183-202

San, İ. (1994). Drama ve öğretim bilgisi. Ankara'da Beşinci Uluslararası Yaratıcı Drama Semineri, (s. 69-81). Ankara.

Soylu Makas, F. (2017). Yaratıcı drama yönteminin dördüncü sinıf matematik dersinde başarı, tutum ve ögrenmenin kalıcılığına etkisi, Yüksek Lisans Tezi, Uludağ Üniversitesi Eğitim Bilimleri Enstitüsü, Bursa

Şengün, Y. (2010). Yaratıcı drama temelli matematik dersinin matematiksel öğrenme ortamları kuramına göre incelenmesi, Yüksek Lisans Tezi, Karadeniz Teknik Üniversitesi Fen Bilimleri Enstitüsü, Trabzon

Üstündağ, T. (1998). Yaratıcı drama eğitim programının öğeleri. Eğitim ve Bilim Dergisi, 28-35.

Yıldırım, A ve Şimşek, H. (2008). Sosyal bilimlerde nitel araştırma yöntemleri, Ankara :Seçkin Yayınlar1 


\section{Extended Abstract}

\section{Introduction}

The importance of basic disciplines such as Science, Technology, Engineering and Mathematics in the developing world is increasing day by day. Mathematics has become an indispensable part of meeting the most basic needs of our daily life as well as the need for mathematics in basic science (Kilıçkaya ve Toptaş, 2017, s. 21). When it comes to mathematics, numbers, shapes, symbols and the rules formed by combining them come to mind. In fact, mathematics is not as complex as it is thought. If the basic grammar rules for that language are learned to learn a language, it can be learned in mathematics in this way (Kösece ve Taşkaya, 2015, s. 958). Today, increasing social needs make it necessary to learn mathematics. One of the ways to learn math is through a good mathematics education.

The most important aim of mathematics education is to solve the problems and problems we encounter in life. It is necessary to understand a problem and relate it to similar problems in our minds and revive the approaches for possible solutions, and continue mental activities until we solve the problem. To be able to do these, it is necessary to be creative. Since the purpose of education is to make the individual ready for life, the methods and techniques used in education should be appropriate for the purpose. For this purpose, many teaching methods and techniques are being developed (Özsoy, 2003 , s. 112). Creative drama method is one of the methods that will enable students to actively participate in the lesson in elementary school mathematics teaching, make their learning fun, increase their self-confidence, improve their creativity, and contribute to their positive attitude towards mathematics.

Creative drama, observation, improvisation, role playing, dramatization, such as using the theater to revive various life situations, to recreate and examine them, to learn from these situations and to learn. Creative drama has proved its usability most in education (San, 1994, s. 69). It can be used as a method in almost every course and subject in creative education.

\section{Method}

In this research, carried out at primary level, based on creative drama to compile teaching mathematics article working to qualitative research methods and literature in Turkey was preferred pattern.

\section{Findings}

Of the 6 studies reached, 5 are articles published in peer-reviewed journals and 1 is a paper presented at scientific meetings. The paper presented at the scientific meetings was produced from a previously written master's thesis. Considering the samples of the studied studies, the opinions of the classroom teachers were taken from the 4th grade five, three in the third grade, two in the first grade, one in the combined classes and in one study.

It is seen that the most used qualitative research method in studies. An article reached is an informative article with a sample lesson on creative drama. Looking at the patterns used in the studies, it was found that case studies were used the most.

Considering the samples of the studied studies, the opinions of the classroom teachers were taken in two classes in the 4th grade, once in the 3rd grade, once in the 1st grade, once in the combined classes and in one study. While the vast majority of the samples were composed of 4th graders, no article work was encountered in the 2 nd grade. It can be said that one of the reasons for making more applications at older grade levels is ease of application.

It is seen that the subjects used in the studies are concentrated in the primary school mathematics lesson "numbers and operations" learning area. This situation may suggest that lessons can only be 
made in the field of learning "numbers and operations" with the creative drama method. However, creative drama is an effective alternative teaching method for many lessons and subjects.

It was concluded that Likert type scales were mostly used as data collection tools in studies. In addition, in the scales, the use of mathematics anxiety, motivation and attitude scales is concentrated.

It was determined that the effect of using creative drama method in primary school mathematics lesson on students' academic achievement, attitudes and permanence of their learning was determined in the studies. In addition, it is seen that the variables in almost all studies repeat each other.

According to the data obtained from the studies, it was seen that 6 studies obtained positive results. Based on this information, it can be said that students 'achievements, attitudes, mathematics motivation, mathematics anxiety and problem solving skills increase, the permanence of learning increases, students' views about mathematics lessons and learning environments have become positive in the lessons taught with the creative drama method.

\section{Conclusion, Discussion and Recommendations}

Of the 6 studies reached, 5 are articles published in peer-reviewed journals and 1 is a paper presented at scientific meetings. The paper presented at the scientific meetings was produced from a previously written master thesis. It is seen that the most used qualitative research method in studies. An article reached is an informative article with a sample lesson on creative drama. Looking at the patterns used in the studies, it was found that case studies were used the most.

When we look at the samples of the studied studies, the opinions of the classroom teachers were taken in two classes in the 4th grade, once in the 3rd grade, once in the 1st grade, once in the combined classes and in one study. It is seen that the subjects used in the studies are concentrated in the primary school mathematics lesson "numbers and operations" learning area.

It was concluded that Likert type scales were mostly used as data collection tools in studies. In addition, in the scales, the use of mathematics anxiety, motivation and attitude scales is concentrated. It was determined that the effect of using creative drama method in primary school mathematics lesson on students' academic achievement, attitudes, and permanence of their learning was determined in the studies. In addition, it is seen that the variables in almost all studies repeat each other.

According to the data obtained from the studies, it was seen that 6 studies obtained positive results. By looking at this information, it can be said that students' achievements, attitudes, mathematics motivation, mathematics anxiety and problem solving skills increase, the permanence of learning increases, student views about mathematics lessons and learning environments have become positive in the lessons taught with the creative drama method.

Based on all these evaluations, we can state the suggestions for using creative drama as a teaching method in elementary school mathematics lesson as follows:

1. It is seen that the sample groups used in the studies are mostly composed of 4 th graders. The creative drama method can be applied to lower level sample groups with appropriate research techniques.

2. Experimental studies comparing creative drama with traditional teaching were achieved in the studies. Alternative techniques to be used in teaching mathematics in accordance with the constructivist approach can be compared with the creative drama method in new researches.

3. As a result of the findings, it is seen that the studies conducted focus on learning numbers and operations. With the creative drama method, studies can be done in other learning areas of the primary school mathematics course.

4. A literature study can be conducted by considering the wider sample group regarding the use of creative drama method in primary school mathematics lesson. 
Ek-1

\section{Ekler}

Tablo 5. İlkokul Matematik Dersinde Yaratıcı Drama ile İlgili İncelenen Çalışmalar

\begin{tabular}{|c|c|c|}
\hline \multicolumn{2}{|l|}{ İncelenen Çalışmanın } & \multirow[t]{2}{*}{ İncelenen Çalışmanın Adı ve Yazarı } \\
\hline Türü & Yılı & \\
\hline \multirow[t]{5}{*}{ Makale } & 2007 & $\begin{array}{l}\text { Matematik Öğretiminde Drama } \\
\text { Nesrin ÖZSOY, Sevgi YÜKSEL }\end{array}$ \\
\hline & 2014 & $\begin{array}{l}\text { Yaratıcı Drama Destekli Matematik Öğretimin Öğrencilerin Akademik Başa- } \\
\text { rısına Etkisi } \\
\text { Vedat AKTEPE, Aydın BULUT }\end{array}$ \\
\hline & 2014 & $\begin{array}{l}\text { Sinıf Öğretmenlerinin Matematik Derslerinde Yaratıcı Drama Yöntemini } \\
\text { Kullanma Durumlarının } \\
\text { İncelenmesi } \\
\text { Murtaza AYKAÇ, Davut KÖĞCE }\end{array}$ \\
\hline & 2015 & $\begin{array}{l}\text { Birleştirilmiş Sınıfı Bir Okulda Drama Yöntemiyle Kesir Öğretiminden Yan- } \\
\text { sımalar: Bayburt Örneği } \\
\text { Mesut ÖZTÜRK, Yaşar AKKAN, Gül KALELİ YILMAZ, Abdullah KAP- } \\
\text { LAN }\end{array}$ \\
\hline & 2016 & $\begin{array}{l}\text { Drama Yöntemiyle Toplama İşlemi: İlkokul Birinci Sınıf Öğrencilerinden } \\
\text { Yansımalar } \\
\text { Mesut ÖZTÜRK, Yaşar AKKAN, Abdullah KAPLAN, } \\
\text { Emre OKTAY }\end{array}$ \\
\hline Bilimsel Toplantılar & 2018 & $\begin{array}{l}\text { Yaratıcı Drama Yönteminin Matematik Kaygısı ve Matematik Motivasyonuna } \\
\text { Etkisi } \\
\text { Gamze BORLAT, İlke EVIN GENCEL }\end{array}$ \\
\hline
\end{tabular}

